\title{
Novel System for Reducing Leaching of the Herbicide Metribuzin Using Clay-Gel-Based Formulations
}

\author{
Celia Maqueda,* Jaime Villaverde, Fátima Sopeña, Tomás Undabeytia, \\ AND ESMERALDA MORILLO
}

Instituto de Recursos Naturales y Agrobiología de Sevilla (CSIC), Apartado 1052, 41080 Sevilla, Spain

\begin{abstract}
Metribuzin is an herbicide widely used for weed control that has been identified as a groundwater pollutant. It contaminates the environment even when it is used according to the manufacturer's instructions. To reduce herbicide leaching and increase weed control, new controlled release formulations were developed by entrapping metribuzin within a sepiolite-gel-based matrix using two clay/herbicide proportions (0.5/0.2 and 1/0.2) (loaded at 28.6 and $16.7 \%$ a.i.) as a gel (G28, G16) or as a powder after freeze-drying (LF28, LF16). The release of metribuzin from the control released formulations into water was retarded, when compared with commercial formulation (CF) except in the case of G28. The mobility of metribuzin from control released formulations into soil columns of sandy soil was greatly diminished in comparison with CF. Most of the metribuzin applied as control released formulations (G16, LF28 and LF16) was found at a depth of $0-8 \mathrm{~cm}$ depth. In contrast, residues from $\mathrm{CF}$ and $\mathrm{G} 28$ along the column were almost negligible. Bioassays from these control released formulations showed high efficacy at $0-12 \mathrm{~cm}$ depth. The use of these novel formulations could minimize the risk of groundwater contamination while maintaining weed control for a longer period.
\end{abstract}

KEYWORDS: Metribuzin; controlled release formulations; soil columns; bioassays; gel

\section{INTRODUCTION}

Specific pesticides have been detected in surface- and groundwaters in different regions of the world $(1,2)$. Water contamination is exacerbated in sandy soils and soils with low organic matter content where herbicide retention capacity of the soil matrix is very poor. Herbicides such as metribuzin (MTB) (3, 4), atrazine, alachlor (5), diuron (6), norflurazon (7-9), which are known to have some degree of persistence in the environment, are among those implicated as groundwater contaminants.

MTB is a herbicide used widely pre- and postemergence for weed control in soybeans, potatoes, tomatoes, and other crops. It has the potential for lateral and downward movement in the soil. Leaching of MTB to lower soil profiles is the main factor responsible for loss in its activity (10).

One approach to minimizing herbicide losses from degradation, volatilization, and leaching is the use of controlled release formulations where the herbicide is incorporated in a matrix and gradually released into the soil $(11-16)$. This leads to a reduction of the herbicide level in the environment because less of the active ingredient needs to be applied to maintain

* Corresponding author: Phone 34-954624711. Fax 34-954624002. E-mail celia@irnase.csic.es. biological efficacy. Dissolved or suspended polymers, surfactants, or pesticide-polymer complexes have been used for reducing volatilization and leaching $(17,18)$. Clay minerals, because of their ubiquitous occurrence in nature, their large specific surface area, and the possibility to modify their surfaces from hydrophilic to hydrophobic, have also been used for controlled release formulations $(14,19)$. Numerous studies have focused on the use of modified montmorillonite by preadsorbing organic cations as a support system for slow release; however, most of the organic cations used in the synthesis of organomontmorillonite complexes are not considered to be of minimal toxicological risk.

Sepiolite is a microfibrous hydrated $\mathrm{Mg}$ phylosilicate with a theoretical unit cell formula $\mathrm{Si}_{12} \mathrm{O}_{30} \mathrm{Mg}_{8}(\mathrm{OH}, \mathrm{F})_{4}\left(\mathrm{OH}_{2}\right)_{4} \cdot 8 \mathrm{H}_{2} \mathrm{O}$ (20) formed by blocks and cavities (tunnels) growing in the direction of the fibers. Each structural block is composed of two tetrahedral silica sheets and a central magnesia sheet. Silanol groups $(\mathrm{Si}-\mathrm{OH})$ are on the external surface of the silicate particles and are accessible to reagents. The tunnels are filled with water molecules coordinated with the $\mathrm{Mg}^{2+}$ ions at the edge of the structure and zeolitic water associated by hydrogen bonding to the former. Sepiolite has a high BET surface area $\left(300 \mathrm{~m}^{2} \mathrm{~g}^{-1}\right)$ that allows for adsorption of water, polar liquids, ions and molecules such as drugs, insecticides, or pesticides. 


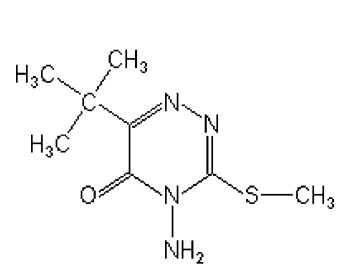

a)

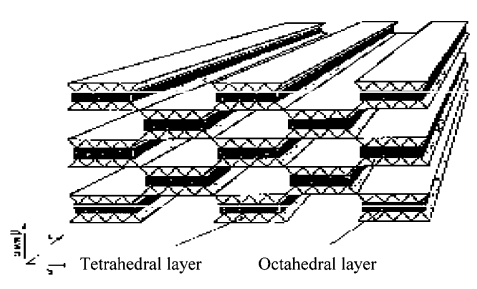

b)
Figure 1. Structural formula of (a) metribuzin and (b) sepiolite structure.

Previous work has been done on the preparation of MTB controlled released formulations through granular formulations of alginate beads, alginate-kaolin-linseed oil, or organomontmorillonite through which the MTB release rate was reduced $(21-24)$, but in all cases the herbicide loading in the formulations was lower than in this research $(1-11.8 \% \mathrm{w} / \mathrm{w})$. On the other hand, there is little data about the environmental behavior in soil and no studies reported about the herbicidal activity of those MTB controlled released formulations.

Taking into account the above considerations, the main objective of this work was to investigate the release mechanism of MTB from sepiolite gel-based formulations prepared in two clay/herbicide proportions (loaded at 28.6 and $16.7 \%$ of herbicide) using a novel, useful, and economical ultrasoundbased technique. The kinetics of herbicide release into water and the influence of freeze-drying the gels on the controlled release of the MTB have also been studied. Then, the new formulations will be tested vs the commercial formulation for leaching and bioactivity in soil column experiments.

\section{MATERIALS AND METHODS}

Materials. Technique grade (93\%) metribuzin (4-amino-6-tert-butyl3-methylthio- 1,2,4-triazin-5(1H)) and commercial formulation (ECLIPSE) in wettable granulate was provided by PRESMAR S. L. The active ingredient (a.i.) content of the herbicide in the commercial product was $70 \%$.

The clay mineral used was a sepiolite from Vicalvaro (Madrid, Spain) obtained from TOLSA S.A. which was crushed to a particle size $<150$ $\mu \mathrm{m}$. Figure 1 shows the sepiolite structure and the structural formula of the herbicide MTB. HPLC-grade acetonitrile, ethanol, and methanol were purchased from Merck (Darmstadt, Germany).

The upper layer $(0-20 \mathrm{~cm})$ of a sandy soil classified as Typic Xeropsament (25) from the experimental farm "La Hampa" in Coria (Seville, Spain) was passed through a $2 \mathrm{~mm}$ sieve before use. The soil was analyzed for $\mathrm{pH}$, total carbonate content, and organic matter. Particle size distribution was measured by a Bouyoucos densimeter (26), and organic matter was measured by $\mathrm{K}_{2} \mathrm{Cr}_{2} \mathrm{O}_{7}$ oxidation, $\mathrm{pH}$ was determined in the 1:2.5 soil/water extract, and total carbonate content was measured by the manometric method (27). The $\mathrm{pH}$ of the soil was 7.8 , and it contained $86 \mathrm{~g} \mathrm{~kg}^{-1}$ calcium carbonate and $7 \mathrm{~g} \mathrm{~kg}^{-1}$ organic matter. The particle size distribution: $27 \mathrm{~g} \mathrm{~kg}^{-1}$ clay, $20 \mathrm{~g} \mathrm{~kg}^{-1}$ silt, and $953 \mathrm{~g} \mathrm{~kg}^{-1}$ sand.

Preparation of Clay/MTB Gel Formulations. The formulations were created by dissolving $200 \mathrm{mg}$ of MTB in $100 \mathrm{~mL}$ of a mixture 80:20 distilled water/ethanol then mixing with 0.5 or $1 \mathrm{~g}$ of sepiolite in a cooling reactor. Afterward, the mixture underwent an ultrasonic treatment, using a Misonix ultrasonic liquid processor of $600 \mathrm{~W}$ output with a $20 \mathrm{kHz}$ converter and a tapped titanium disruptor horn of 12.7 $\mathrm{mm}$ in diameter in order to obtain a gel texture. The horn tip was dipped into the cylinder jacketed cooling cell with $5 \mathrm{~cm}$ internal diameter. The dispersions were sonicated for $45 \mathrm{~min}$. The temperature of the reactor was kept constant at $20{ }^{\circ} \mathrm{C}$ by means of a cooling recirculation during the entire treatment. The resulting formulations denoted as G16 and G28 contained 16.7 and $28.6 \%$ active ingredient (a.i.), respectively.

Freeze-Dried Herbicide Clay-Gel Formulations. Part of each resulting clay-gel formulations was air-dried in order to evaporate ethanol, placed in a freezer for $24 \mathrm{~h}$, and freeze-dried (formulations denoted as LF16 and LF28). The freeze-drying treatment was performed in Virtis Sentry $5 \mathrm{~L}$ equipment. After the formulations were freezedried, MTB was extracted with methanol $(1: 2 \mathrm{w}: \mathrm{v})$ with the aim of checking possible herbicide losses. More than $95 \%$ of MTB was recovered.

Water Release Studies. To compare the release behavior of the different formulations dissolution tests of the commercial MTB and all clay-based formulations (G16 and G28 as gel and LF16 and LF28 as powder after freeze-drying) were performed in triplicate with a rotate paddle apparatus (Sotax). Formulations containing $10 \mathrm{mg}$ of MTB were added to $500 \mathrm{~mL}$ of deionized water as a dissolution medium, the stirring speed was $50 \mathrm{rpm}$, and the temperature was maintained at 25 ${ }^{\circ} \mathrm{C} \pm 5{ }^{\circ} \mathrm{C}$. The gel formulations were placed in dialysis bags (MWCO: 100) supplied by Spectrum Laboratory, and the freeze-dried formulations were added directly to the water as a powder. At appropriate intervals, over $100 \mathrm{~h}, 1 \mathrm{~mL}$ samples were taken and replaced by distillate water in order to maintain a constant volume. The samples were analyzed by HPLC as described below.

Leaching Experiments in Soil Columns. Leaching experiments were done in duplicate for the selected soil. Homogeneous soil columns were prepared by packing the soil gently and uniformly in $18-\mathrm{cm}$ long methacrylate tubes of $3.0 \mathrm{~cm}$ internal diameter. The lower end was covered with nylon tissue and padded with a thin layer of glass wool $(0.5 \mathrm{~g})$ to hold the soil firmly into the column. Each column was filled with $164 \mathrm{~g}$ of soil to achive $16 \mathrm{~cm}$ occupied by soil.

In a preliminary experiment, two soil columns of the soil were saturated by capillarity with distilled water to obtain a moisture content of $100 \%$ of the field capacity for the soil colunm. The difference between the weight of the saturated soil column and its dry weight was used to calculate the value for one pore volume $(45 \mathrm{~mL})$.

Soil columns were treated with five pore volumes of a $0.01 \mathrm{M} \mathrm{Ca}$ $\left(\mathrm{NO}_{3}\right)_{2}$ solution to equilibrate them with the background electrolyte, subsequently metribuzin formulation equivalent to $2 \mathrm{~kg} \mathrm{ha}^{-1}$ of MTB (a.i) which is in the range used in the field $\left(0.84-3 \mathrm{~kg} \mathrm{ha}^{-1}\right)$ (28) was applied. After herbicide application, a 1-cm layer of sand was added on top of each column and then covered with glass wool to prevent disturbances of the soil by the input liquid.

Breakthrough curves (BTCs) were obtained through daily application of $25 \mathrm{~mL}$ distilled water until herbicide was no longer detected in the leachates (12 days). MTB in the daily leaches was monitored by HPLC.

After the leaching experiments, the columns were sliced into four 4 $\mathrm{cm}$ segments and the soil was air-dried at $40{ }^{\circ} \mathrm{C}$. The herbicide residues that remained adsorbed in the soil from each segment were extracted using $5 \mathrm{~mL}$ of methanol (ratio 2:1/ soil: solution) with shaking for $24 \mathrm{~h}$, this process was repeated three times, and the total volume of extractant was evaporated to $1 \mathrm{~mL}$. Afterward, samples were stored in a freezer until analyzed by GC/MS as described below.

Herbicidal Activity of MTB formulations. In order to investigate the herbicidal activity of the controlled released formulations along the length of the soil column, a bioassay based on the bleaching effect on plants was used. Three soybean seeds were placed in $5 \mathrm{~g}$ of soil (from each segment) in a plastic container of $3 \mathrm{~cm}$ diameter and then covered with another $5 \mathrm{~g}$ of the soil. The soil samples were placed in a growth chamber at $25 \pm 3{ }^{\circ} \mathrm{C}$ with a photoperiod of $16 \mathrm{~h}$ of light at an intensity of $11 \mu \mathrm{E} / \mathrm{m}^{2} \mathrm{~s}$ and moistened with water every day over the ten days of the experiment. The untreated control was handled identically to the plants treated with herbicide.

The bleaching effect on soybeans was obtained by measuring the chlorophyll content of the plant shoot and determining the inhibition percentage as compared with the herbicide-untreated control.

Chlorophyll content was determined by cutting the fresh shoot of soybean plants and extracting the chlorophyll with $15 \mathrm{~mL}$ of $N, N$ dimethylformamide. The extracts were incubated for $48 \mathrm{~h}$. Chlorophyll content was measured by visible spectroscopy at 664 and $647 \mathrm{~nm}$ and related to the weight of the fresh shoot. Each experiment was carried out in quadruplicate. A dose-response curve was established, shaking $10 \mathrm{~g}$ of the selected soil thoroughly for $24 \mathrm{~h}$ with appropriate amounts of the herbicide to achieve concentrations between 0 and $2.8 \mathrm{mg} \mathrm{kg}^{-1}$. This procedure was intended to measure the bleaching effect in the plants as a result of the herbicide concentration in the soil. The data 


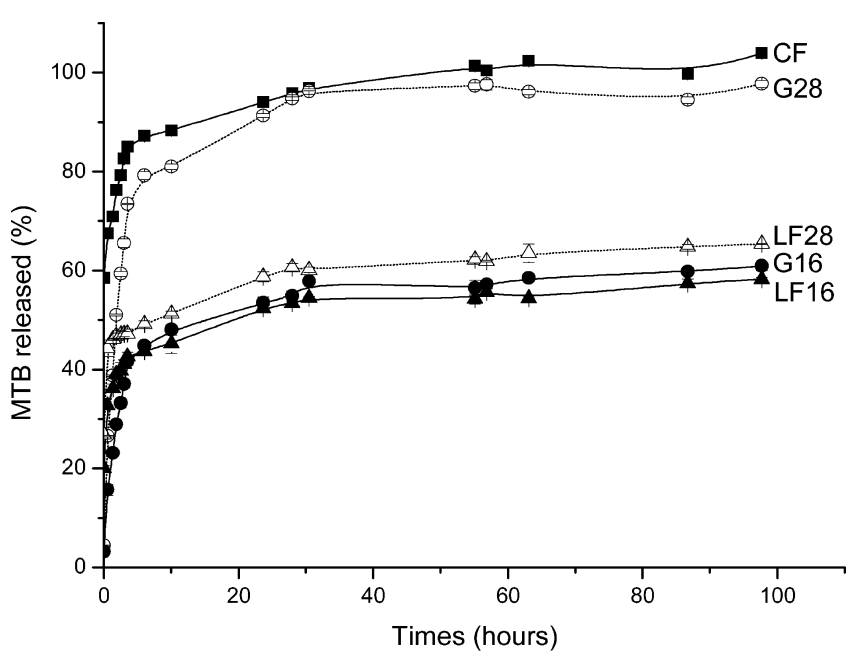

Figure 2. Amount of metribuzin released into water from the different formulations obtained.

obtained were used for regression analysis to estimate the $\mathrm{CL}_{50}$ (herbicide required to create $50 \%$ chlorophyll inhibition). Different equations were tested to describe the relationship between inhibition (\%) and herbicide concentration $(\mathrm{mg} / \mathrm{kg}$ ) using the Excel solver tool. The equation with the highest $R^{2}$ value was chosen as the most appropriate.

Analytical Techniques. HPLC was employed for metribuzin analyses except in those samples from soil columns extracted with methanol. The conditions were as follows: mobile phase, acetonitrile: water (60:40); flow, $0.6 \mathrm{~mL} / \mathrm{min}$; temperature, $30^{\circ} \mathrm{C}$; chromatographic column kromasil C18 reverse phase; UV detector (Shimadzu 2010 AHT series), wavelength of $254 \mathrm{~nm}$.

MTB from methanol extraction was analyzed by CG-MS coupled to an Agilent automass quadrupole mass spectrometer. Since the extracted residues from some formulations were found in a very low amount (under the HPLC detection limit) in the different rings from the soil columns, a $6890 \mathrm{~N}$ gas chromatograph from Agilent Technologies 5975 series was employed because of its higher sensitivity. An agilent Automass quadrupole mass spectrometer was used for detection. Injection was in splitless mode with the split valve closed for $48 \mathrm{~s}$. Helium was employed as a gas carrier. A Hewlett-Packard DB $17 \mathrm{~ms}$ (30 $\mathrm{cm} \times 0.25$ i.d. $\times 0.17 \mu \mathrm{m}$ film thickness) capillary column was used. The temperature program for the chromatographic run was the following: $T_{\mathrm{o}}=50{ }^{\circ} \mathrm{C} ; T_{0}-T_{1}, 30{ }^{\circ} \mathrm{C} \min ^{-1}, T_{1}=190{ }^{\circ} \mathrm{C} \min ^{-1} ; T_{1}$ $-T_{2}, 10{ }^{\circ} \mathrm{C} \min ^{-1}, T_{2}=200{ }^{\circ} \mathrm{C} \min ^{-1} ; T_{2}-T_{3}, 2{ }^{\circ} \mathrm{C} \min ^{-1}, T_{3}=$ $210{ }^{\circ} \mathrm{C}$ (hold $3 \mathrm{~min}$ ); a cleaning step $T_{3}-T_{4}, 30^{\circ} \mathrm{C} \min ^{-1}, T_{4}=280$ ${ }^{\circ} \mathrm{C} \min ^{-1}$ was also included. For mass spectrometric detection, a potential of $70 \mathrm{eV}$ was initially imposed in total ion scan or full scan $(\mathrm{m} / \mathrm{z}, 45-300)$. Then, acquisition was performed under time-scheduledselected ion monitoring (SIM) using the following ions: 103, 144, and $74 \mathrm{~m} / \mathrm{z}$ for metribuzin quantification. The MS detector was kept at 200 ${ }^{\circ} \mathrm{C}$. In order to avoid saturation and to preserve it, the analyzer was switched off for 4 min during solvent elution and after the last eluting analyte determination. The limit of quantification was $1 \mu \mathrm{g} / \mathrm{g}$ of soil, and the recoveries were $91-112 \%$.

Fourier Transform Infrared Spectroscopy. Fourier transform infrared (FTIR) spectra of MTB, sepiolite, herbicide formulations, and physical mixtures at the same sepiolite/MTB ratios as the formulations were recorded in $\mathrm{KBr}$ pellets (2 wt $\%$ sample) using a Nicolet spectrometer $(20 \mathrm{SXB})$ in the range of $4000-400 \mathrm{~cm}^{-1}$.

\section{RESULTS AND DISCUSSION}

Water Release Experiments. The amount of MTB released into the water phase from all formulations (CF, G28, G16, LF28, and LF16) in $100 \mathrm{~h}$ tests is shown in Figure 2. The release of MTB from the controlled release formulations was retarded when compared with that of the commercial formulations, except for the G28 formulation, which showed retarded release only in the first few hours. All formulations showed a fast release of MTB in the first hours, related to the high water solubility (1.05 $\mathrm{g} \mathrm{L}^{-1}$ at $20^{\circ} \mathrm{C}$ ) of MTB. The cumulative percentage of MTB released after $100 \mathrm{~h}$ was selected to compare the influence of type of formulations and herbicide loading on the release kinetics. From CF the $80 \%$ of herbicide was released in the first minute of the experiment. The G28 formulation showed a final release similar to that of CF $(\sim 100 \%)$, but with different initial releases, until $24 \mathrm{~h}$ of starting the experiment. The release profiles of G16 and LF formulations were characterized by a similar final release, after $100 \mathrm{~h}$, but displayed different releases in the first few hours of the experiment. At the beginning of the experiment the amount of MTB released ranged from $3 \%$ to $20 \%$ to $26.8 \%$ of the herbicide present in the formulations for G16, LF28, and LF16, respectively. The release patterns for these formulations depended not only on the type of preparation but also on herbicide loading, especially in the case of the gelling formulations. Thus, initial release after $30 \mathrm{~min}$ decreased in the following order CF $>$ LF16 $>$ LF28 $>$ G28 $>$ G16. These results indicate that a range of rates and extents of MTB release can be achieved by selecting the type of preparation (LF or G) and herbicide loading in the gel-clay system. This suggests that it may be possible to select diverse preparations according to use.

The release rates of the gel formulations were affected dramatically by the clay/MTB ratio. The gels prepared using $0.5 \mathrm{~g}$ of sepiolite (G28) presented lower viscosity than those prepared with $1 \mathrm{~g}$ of sepiolite. The diffusion of the herbicide from G28 is favored over the higher viscosity formulation (G16).

In contrast, the freeze-dried formulations (LF28 and LF16) showed similar behavior with regard to the release of MTB percentage, independent of the clay/MTB ratio. This behavior indicates the influence on the release of the freeze-dry process applied to the formulations. The sepiolite presents nanostructured tunnels measuring $3.7 \times 10.6 \AA$ in cross-section that are able to incorporate organic compounds in the tunnels (20) and hold the compounds tightly bounded. This could explain the decrease in release for these formulations and the constant release for several hours during the experiment. To check these FTIR spectra were recorded for both formulations, physical mixtures at the same clay/MTB ratio, and for the freeze-dried gels without pesticide. The absorption band at $3720 \mathrm{~cm}^{-1}$ assigned to the $\mathrm{OH}$ streching vibration of silanol groups, the bands at $3680 \mathrm{~cm}^{-1}$ corresponding to $\mathrm{Mg}-\mathrm{OH}$ vibration inside the sepiolite block, and the bands at 3630 and $3550 \mathrm{~cm}^{-1}$ assigned to the coordinate water molecules $\left(v_{\mathrm{OH}}\right)$ remained unaffected (data not shown), indicating an absence of water bridges linking $\mathrm{Mg}^{2+}$ with the MTB inside the tunnels. Therefore, FTIR spectra showed that there is no evidence of herbicide inside the sepiolite tunnels.

Freeze-drying could affect the release rate of MTB from the LF formulation because of collapse of the fibers during this treatment, which would strongly entrap the herbicide and impede its release into water.

The release kinetics of MTB from the controlled release formulations were fitted to a first-order kinetics equation and the $\mathrm{T}_{\mathbf{5 0}}$ values (time taken for $50 \%$ of a.i to be released) were estimated. The $T_{50}$ values were 17.5 and $0.97 \mathrm{~h}$ for G16 and $\mathrm{G} 28$, respectively, indicating a decrease in MTB release for the gel formulation with a higher sepiolite proportion. The two LF formulations showed $T_{50}$ values of 19.0 and $7.82 \mathrm{~h}$ for LF16 and LF28, respectively. The data show that MTB water release is affected more significantly by type of formulation than herbicide loading. CF formulation presented $80 \%$ release within the first minute. 

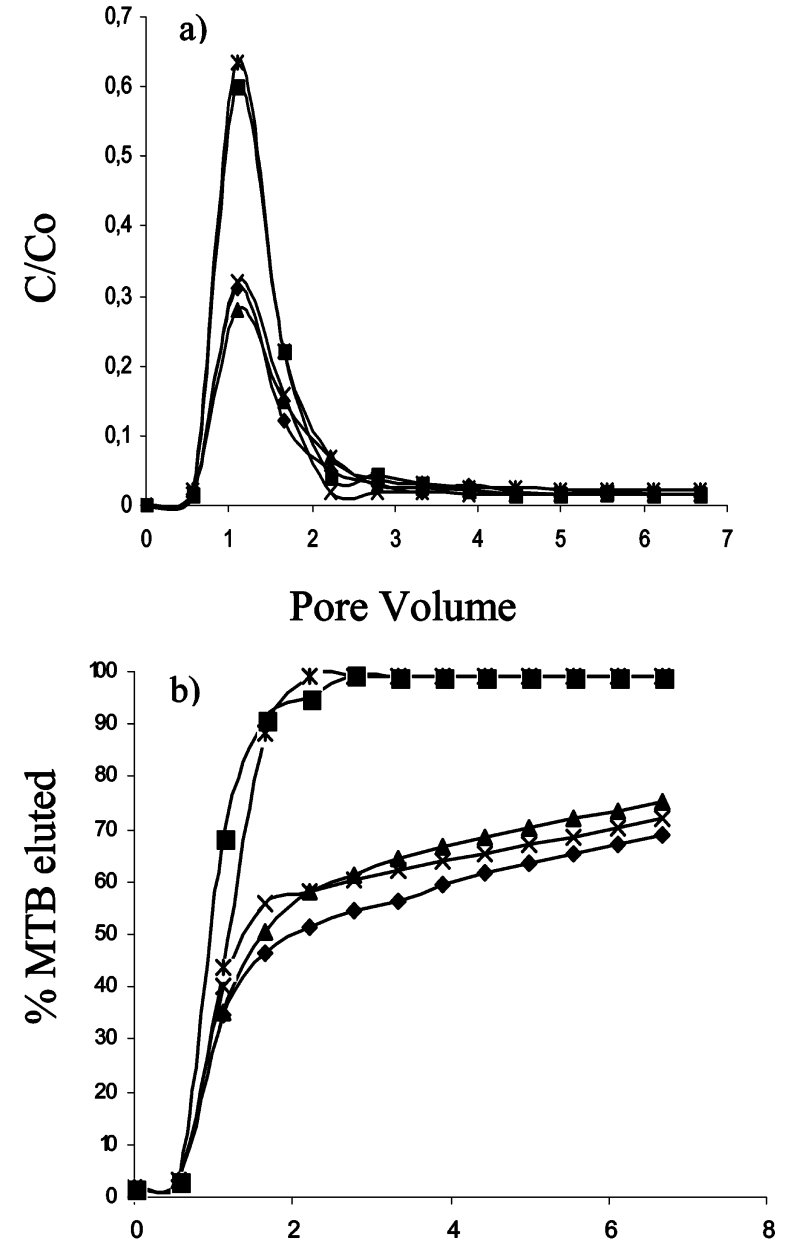

Pore Volume

Figure 3. Breakthrough curves (a) and cumulative percentage (b) of metribuzin leached from soil columns using the different formulations, CF

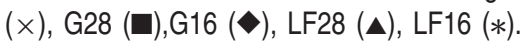

Mobility Studies. Breakthrough curves and cumulative percentage of MTB leached from soil columns using the different formulations in sandy soil columns are shown in Figure 3. The amount of MTB added to the soil columns was equivalent to the recommended amount for application on agricultural soils $\left(2 \mathrm{~kg} \mathrm{ha}^{-1}\right)$. The total percentage of MTB eluted from the CF and G28 formulations was close to $100 \%$ of the total applied. This result is in agreement with the low MTB adsorption observed in previous research using sandy soils $\left(K_{\mathrm{d}}=0.246\right)(29)$, MTB has a high affinity for soil organic matter (the soil used in this work has very low organic matter), and its adsorption decreases in basic conditions $(30,31)$. The $\mathrm{pH}$ of our soil was 7.8.

After four pore volumes (255 $\mathrm{mm}$ of rain), where almost complete leaching of the $\mathrm{CF}$ and $\mathrm{G} 28$ formulations occurred $(99.0 \pm 1.2 \%$ and $94.0 \pm 3.2 \%$, respectively), the total leaching percentages of the other gel-clay-based formulations were 57.1 $\pm 1.9,54.9 \pm 2.4$, and $53.2 \pm 2.8$ for LF16, LF28, and G16, respectively. Similar behavior was observed when the release rate profiles into water were compared, which indicates a clear correlation between MTB release into water and its capacity to be leached in soil columns. It also seems likely that the leaching pattern can be controlled by varying not only the type of formulation but also the clay /herbicide ratio.

The MTB residues extracted from the different rings of the soil columns are shown in Figure 4. The values for the CF and

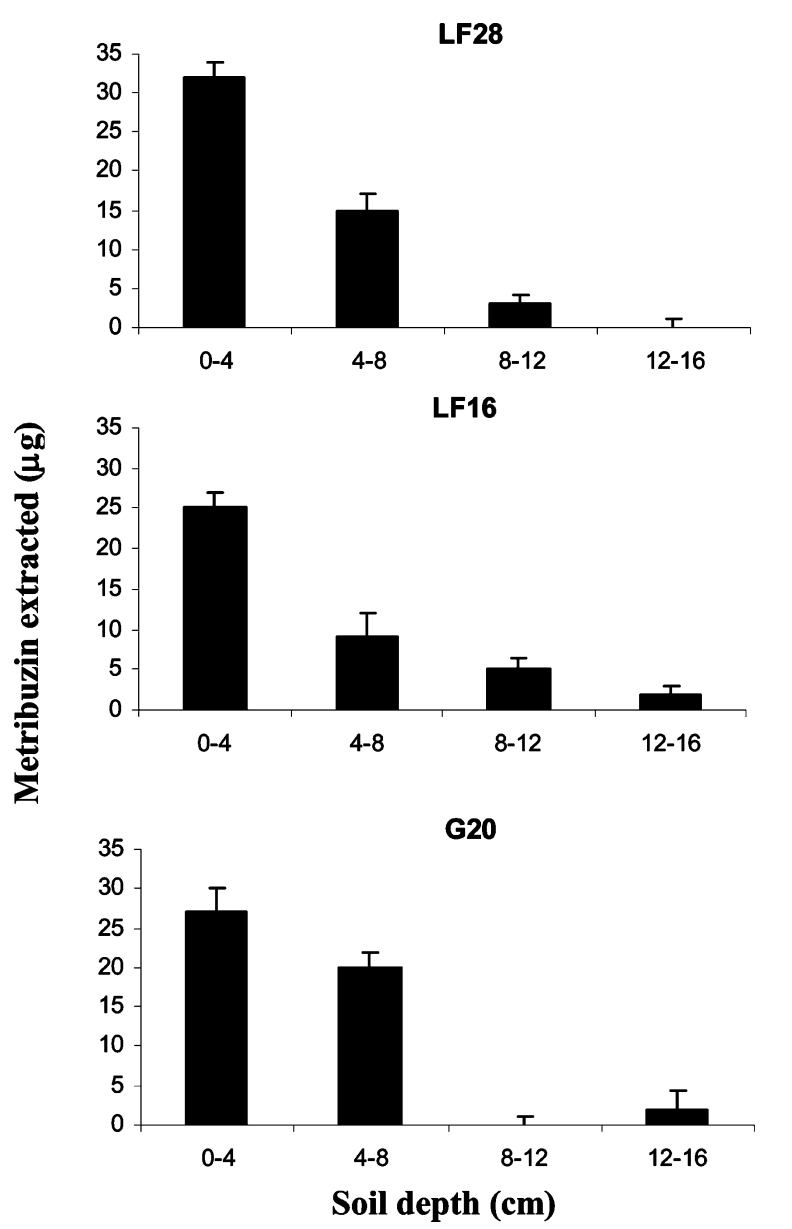

Figure 4. Metribuzin residues extracted at different depth of the soil columns.

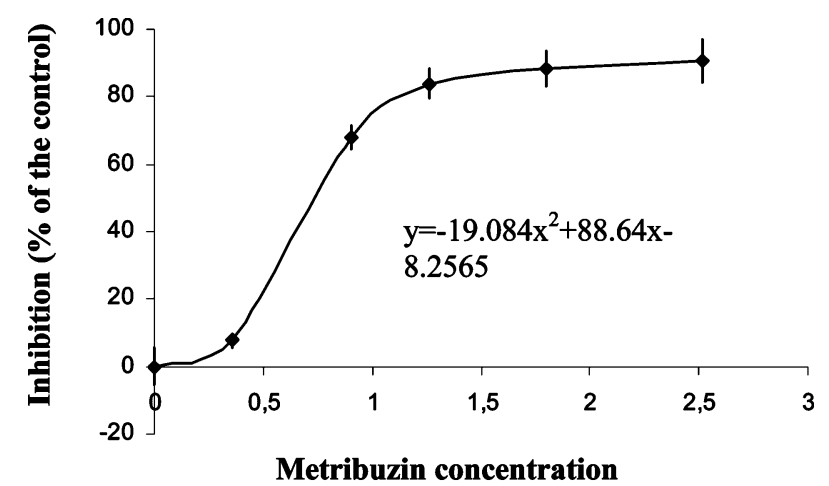

Figure 5. Chlorophyll inhibition (percent of the control) in the selected soil versus metribuzin concentration $\left(\mathrm{mg} \mathrm{kg}^{-1}\right)$.

G28 formulations are not presented, because no residue was detected along the soil columns. Most of the residues for the rest of the formulations were found in the first two rings of the soil columns. The deeper the soil ring, the lower the amount of the herbicide residues found. The reduction of MTB release rate into water is closely related to the potential capacity for biological effectiveness, since most MTB residue remained in the top layers $(1-8 \mathrm{~cm}$ depth), which is desirable for weed control.

Herbicidal Activity. The biological activity of MTB was tested by measuring chlorophyll inhibition through the bleaching intensity created in the soybean plants after herbicide application. Figure 5 shows the effect of the amount of herbicide in soil on the inhibition percentages of soybeans plants as compared to a control without herbicide. Inhibition was increased (but not 

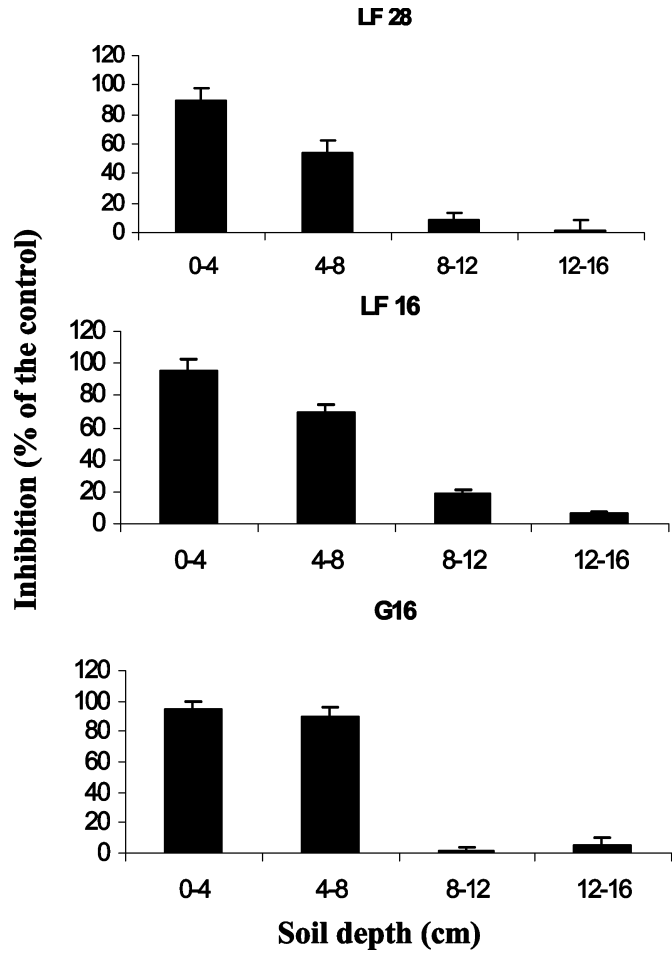

Figure 6. Chlorophyll inhibition as a function of the depth of the soil columns.

proportionally) by increasing herbicide concentrations. Regression analysis of chlorophyll inhibition versus herbicide concentration in soil gave the corresponding equation that provided the best fit for this soil (Figure 5). Using this equation, the $\mathrm{CL}_{50}$ (MTB required for the $50 \%$ of chlorophyll inhibition) was determined to be $0.88 \mathrm{mg}$ a.i. $\mathrm{kg}^{-1}$.

Herbicidal activity was also measured at different depths of the soil column to find a correlation between the remaining MTB residues and their biological activity (Figure 6). A clear correlation could be confirmed by comparing Figures $\mathbf{4}$ and $\mathbf{6}$. No bleaching effect was detected for the formulations where all the herbicide was leached in the soil columns (CF, G28) (data not shown). To the contrary, in the cases of LF28, LF16, and G16, higher herbicidal activity could be observed in the first depth segments studied. These three formulations present very good herbicidal activity.

Overall, slow release formulations should be designed to reach a compromise between reduction in leaching and maximal herbicidal activity in the top soil layer. The clay-based formulations (LF28, LF16, and G16) fulfill both of these requirements, the amount of herbicide leached was reduced, and biological activity was improved in the upper layer of the soil. Therefore, rates of MTB application from the novel clay-based formulations can be lower than those applied with the commercial formulation, which is important from an economical and environmental point of view.

\section{ACKNOWLEDGMENT}

We are indebted to Presmar S.L. for providing metribuzin and to Tolsa S.A. for the sepiolite used.

\section{LITERATURE CITED}

(1) Boparai, H.; Shea, P.; Comfort, S.; Snow, D. Dechlorinating chloroacetanilide herbicides by dithionite-treated aquifer sediment and surface soil. Environ. Sci. Technol. 2006, 40, 3043-3049.
(2) Konstantinou, I.; Hela, D.; Albanis, T. The status of pesticide pollution in surface waters (rivers and lakes) of Greece. Environ. Pollut. 2006, 141, 555-570.

(3) Hallberg, G. R. Pesticide pollution of groundwater in the humid united-states. Agric. Ecosys. Environ. 1989, 26, 299-367.

(4) Maloschik, E.; Erns, A.; Hegeduss, G.; Darvas, B.; Szekacs, A. Monitoring water-polluting pesticides in Hungary. Microchem. J. 2007, 85, 88-97.

(5) Laabs, V.; Wehrhan, A.; Pinto, A.; Dores, E.; Amelung, W. Pesticide fate in tropical wetlands of Brazil: An aquatic microcosm study under semi-field conditions. Chemosphere. 2007, 67, 975989.

(6) Fava, L.; Orru, M. A.; Businelli, D.; Scard, S.; Funari, E. Leaching potential of some phenylureas and their main metabolites through laboratory studies. Environ. Sci. Pollut. Res. 2006, 13, 386-39.

(7) Undabeytia, T.; Nir, S.; Rubin, B. Organo-clay formulations of the hydrophobic herbicide norflurazon yield reduced leaching. $J$. Agric. Food Chem. 2000, 48, 4767-4773.

(8) Sopeña, F.; Maqueda, C.; Morillo, E. Norflurazon mobility, dissipation, activity, and persistence in a sandy soil as influenced by formulation. J. Agric. food Chem. 2007, 55, 3561-3567.

(9) Villaverde, J. Time-dependent sorption of norflurazon in four different soils: Use of beta-cyclodextrin solutions for remediation of pesticide-contaminated soils. J. Hazard. Mater. 2007, 14, 184190.

(10) Peek, D. C.; Appleby, A. P. Effect of pH on phytotoxicity of metribuzin and ethyl-metribuzin. Weed Tech. 1989, 3, 636-639.

(11) Sopeña, F.; Cabrera, A.; Maqueda, C.; Morillo, E. Controlled release of the herbicide norflurazon into water from ethylcellulose formulation. J. Agric. Food Chem. 2005, 535, 3540-3547.

(12) Undabeytia, T.; Mishael, Y. G.; Nir, S.; Papahadjopoulos, T.; Rubin, B.; Morillo, E.; Maqueda, C. A novel system for reducing leaching from formulations of anionic herbicides: Clay-liposomes. Environ. Sci. Technol. 2003, 3, 4475-4480.

(13) Garrido-Herrera, F. J.; Gonzalez-Pradas, E.; Fernandez-Perez, M. Controlled release of isoproturon, imidacloprid, and cyromazine from alginate-bentonite-activated carbon formulations. J. Agric. Food Chem. 2006, 54, 10053-10060.

(14) Hermosin, M. C.; Celis, R.; Facenda, M. J.; Carrizosa, M. J.; Ortega-Calvo, J. J.; Cornejo, J. Bioavailability of the herbicide 2,4-D formulated with organoclays. Soil Biol. Biochem. 2006, 38, $2117-2124$.

(15) Sopeña, F.; Cabrera, A.; Maqueda, C.; Morillo, E. Ethylcellulose formulations for controlled release of the herbicide alaclor in a sandy soil. J. Agric. Food. Chem. 2007, 55, 8200-8205.

(16) Sopeña, F.; Maqueda, C.; Morillo, E. Influence of soil characteristics and formulation on alachlor dissipation in soil. Soil Sci. Soc. Am. J. 2008, 72, 767-774.

(17) Moore, C. E.; Chow, V. S.-C.; Hopkinson, M. J.; Shannon, T. T. Pesticide formulations containing alkoxylated tristyrylphenol hemisulfate ester neutralized alkoxylated amine surfactants. U.S. Patent Document 6,495,595 B2, 2002.

(18) Green, J. M.; Beestman, G. B. Recently patented and commercialized formulation and adjuvant technology. Crop Prot. 2007, 26, 320-327.

(19) Sanchez-Verdejo, M. T.; Undabeytia, T.; Nir, S.; Maqueda, C.; Morillo, E. Environmentally friendly show release formulations of alachlor based on clay-phosphatidylcholine. Environ. Sci. Technol. 2008, 42, 5779-5784.

(20) Kuang, W. X.; Facey, G. A.; Detellier, C.; Casal, B; Serratosa, J. M. Ruiz-Hitzky. Nanostructured hybrid materials formed by sequestration of pyridine molecules in the tunnels of sepiolite. Chem. Mater. 2003, 15, 4956-4967.

(21) Pepperman, A. B.; Kuan, J. W. Slow release formulations of metribuzin based on alginate-kaolin -linseed oil. J.Cont. Rel. 1993, $26,21-30$

(22) Selin, H. M.; McGowen, S. L.; Johnson, R. M.; Pepperman, A. B. Fate of metribuzin from alginate controlled formulations in a sharkey soil: 2. Transport. Soil Sci. 1998, 16, 535-543. 
(23) Singh, N. Reduced downward mobility of metolachlor and metribuzin from surfactant-modified clays. J. Environ. Sci. Health, Part B: 2006, 41, 17-29.

(24) Flores-Cespedes, F.; Villafranca-Sanchez, M.; Perez-Garcia, S.; Fernandez-Perez, M. Modifying sorbents in controlled release formulations to prevent herbicides pollution. Chemosphere 2007, 6, 785-94.

(25) Soil Survey Staff. Key to Soil Taxonomy, 10th ed.; NRCS: Washington, DC, 2006.

(26) Gee, G. W.; Bauder, J. W., Particle-size analysis. In Methods of Soil Analysis: Part 1. Physical and Mineralogical Methods; Klute, A., Ed.;Agronomy series no. 9, American Society of Agronomy: Madison, WI, 1986; pp 383-411.

(27) Demolon, A.; Leroux, D. Guide pour l'estude Experimental des sols; Gautier Villars: Paris, 1952.

(28) Tomlin, C. D. S., Eds. The e-Pesticides Manual: a world compendium; The British Crop Production Council: Hamshire, UK, 2006.
(29) Wauchope, R. D.; Buttler, T. M.; Hornsby, A. G.; Augustijnbeckers, P. W. M.; Burt, J. P. The SCS ARS CES pesticide properties database for environmental decision-making. Rev. Environ. Contam. Toxic. 1992, 123, 1-155.

(30) Ladlie, J. S.; Meggitt, W. F.; Penner, D. Effect of Soil-pH on microbial-degradation, adsorption, and mobility of metribuzin. Weed Sci. 1976, 24, 477-481.

(31) Savage, K. E. Adsorption and mobility of metribuzin in soil. Weed Sci. 1976, 24, 525-528.

Received for review July 30, 2008. Revised manuscript received October 6, 2008. Accepted October 7, 2008. This work has been supported by MEC (Spanish Ministry of Education and Science) through Research Projects AGL 2005-00164 and by Junta de Andalucía (Project P06-FQM-01909).

JF802364T 